\title{
Phaeohyphomycosis: a clinical-epidemiological and diagnostic study of eighteen cases in Rio Grande do Sul, Brazil
}

\author{
Cecília Bittencourt Severo', Flávio de Mattos Oliveira', \\ Emily Ferreira Salles Pilar², Luiz Carlos Severo, ${ }^{1,3}+$
}

Laboratório de Micologia ${ }^{2}$ Laboratório de Patologia, Irmandade Santa Casa de Misericórdia de Porto Alegre, Porto Alegre, RS, Brasil ${ }^{3}$ Departamento de Medicina Interna, Universidade Federal do Rio Grande do Sul, Porto Alegre, RS, Brasil

The goal of this study was to review 18 cases of phaeohyphomycosis in Rio Grande do Sul. The records of all of the patients with a diagnosis of phaeohyphomycosis between 1995-2010 were reviewed. Twelve of the 18 patients (66.6\%) were male. The average age of the patients was 50 years old (range: 16-74 years). Eleven patients (61\%) presented with subcutaneous lesions. Seven patients (38.8\%) had received a solid organ transplant. In all of the cases, the presence of melanin in the fungal cells was determined by Fontana-Masson staining of tissue sections and documented. Among the 18 patients, a total of 11 different fungal species were isolated. The causative organisms included Exophiala jeanselmei, Alternaria, Curvularia, Cladophialophora and Colletotrichum gloeosporioides. To our knowledge, this review reports the first case of subcutaneous phaeohyphomycosis caused by $\mathrm{C}$. gloeosporioides in a lung transplant patient. The number of reported cases of phaeohyphomycosis has increased in the last decade. In a number of cases, this increased incidence may be primarily attributed to iatrogenic immunodeficiency.

\section{Key-words: phaeohyphomycosis - solid organ transplants - Exophiala jeanselmei - Alternaria sp. -}

Curvularia sp. - Colletotrichum gloeosporioides

The term phaeohyphomycosis (from the Greek phaios, meaning dark or darkish) was introduced by Ajello et al. in 1974 to designate infections by phaeoid or pigmented filamentous fungi that contain melanin in their walls. These microorganisms are saprobes in nature, found in wood and decomposing plants. Superficial cutaneous and corneal manifestations of the mycosis are more frequent and develop among healthy individuals. The designations of tinea nigra, black piedra and mycotic keratitis, which are commonly used, should not be replaced by phaeohyphomycosis (McGuinnis 1983). Cutaneous and systemic phaeohyphomycosis occur in immunocompromised patients. These infections are considered to be rare (Rossman et al. 1996).

Microscopically, the aetiological agents present as yeast elements, pseudo-hyphae, septate hyphae, ramified hyphae (short or long; regular or curled) or a combination of these findings with a brownish colouration (Mostert et al. 2005). The main genera involved include Alternaria, Bipolaris, Cladophialophora and Exophiala (Matsumoto \& Ajello, de Hoog et al. 2000). Phaeohyphomycosis can be distinguished from two other subcutaneous mycoses caused by phaeoid fungi: Chromoblastomycosis and Mycetoma. The differential diagnosis is established by the presence of muriform cells (sclerotic bodies) or black grains in cases of chromoblastomycosis and mycetoma, respectively (McGuinnis 1983).

Financial support: CAPES, CNPq

+ Corresponding author: severo@pesquisador.cnpq.br

Received 28 November 2011

Accepted 16 July 2012
The laboratory diagnosis is first based on the morphological characteristics of the agents as observed by direct microscopic examination and histopathology. The diagnosis is necessarily supported by the examination of cultures to identify the genus and species of the aetiological agent (Lacaz et al. 2002). The rarity of this mycosis justifies describing the clinical, epidemiological and diagnostic characteristics to aid in its immediate recognition and early treatment.

\section{SUBJECTS, MATERIALS AND METHODS}

In this study, we retrospectively reviewed the clinical data, epidemiological data and diagnoses of 18 cases of phaeohyphomycosis identified between 1995-2010 by the Mycology Laboratory of the Santa Casa Medical Centre, Porto Alegre, Rio Grande do Sul (RS), Brazil. The medical records of all of the patients were analysed in relation to sex, age, race, predisposing diseases, anatomical location and time elapsed between the manifestation of the disease and its diagnosis. The study was approved by the Committee of Research and Ethical of Santa Casa Medical Centre (protocol 3098/89).

Laboratory diagnosis - Fragments of surgically removed tissue were submitted for histological processing, maintained within paraffin blocks and stained by standard techniques for haematoxylin and eosin (H\&E), Grocott methenamine silver (GMS) (useful in the study of fungal micromorphology) and the Fontana-Masson (FM) special technique, which detects the presence of melanin in fungal walls (Wood \& Russel-Bell 1983, Kimura \& McGinnis 1998). The direct examination of the tissue fragments was performed by mounting and clarification in a solution of $10 \%$ potassium hydroxide. The macroscopic evaluation identified colony morphol- 
ogy varying from yeast-like to velvety (depending on the species) and olive-brown to black, when incubated at $25^{\circ} \mathrm{C}$ in Sabouraud agar with or without antibiotics and BBL ${ }^{\mathrm{TM}}$ Mycosel $^{\mathrm{TM}}$ agar. The cultures were maintained from twofour weeks. For the examination of microscopic morphology, the isolates were submitted to cultures in blades using potato agar. The identification of genus and species was based on various morphological characteristics.

\section{RESULTS}

Most of the patients were male (12/18) and between 16-74 years of age (average 50 years) and all of the patients were Caucasian. The most frequently observed symptom was subcutaneous nodules $(11 / 18 ; 61 \%)$ and the most commonly associated or predisposing condition was solid organ transplantation (7/18; 38.8\%) (Table).

The lesions were present on the lower limbs in $62 \%$ $(10 / 18)$ of the cases (Fig. 1A). In one cerebral lesion in the subarachnoid space and fourth ventricle (case 10), a greenish purulent material with dark punctate areas caused by melanin in the fungal wall was observed (Fig. 2A).

Granulomatous inflammation with epithelioid histiocytes and giant cells was observed in all of the cases. In seven cases, necrotising granulomatous inflammation with suppuration was observed. Central areas of necrosis and marginal areas of fibrosis were present in six cases. Pigmented spherical structures (Figs 1B, 3A) and filaments (Figs 2B, 3B) were detected in the inflammatory areas. In one case, the fungal elements were hyaline (case 12). Under microscopy, the fungi were observed either as isolated cells or inside giant cells (phagocytes). When stained with GMS silver stain, the fungal structures were well defined. In all of the cases, numerous polymorphic elements were observed, including yeast (dilated or irregularly shaped, some with budding), pseudo-hyphae and simple or ramified hyphae (short or long; regular or curled) (Fig. 4A). In all of the cases, there was a positive melanin reaction as detected by FM staining of the fungi (Fig. 4B).

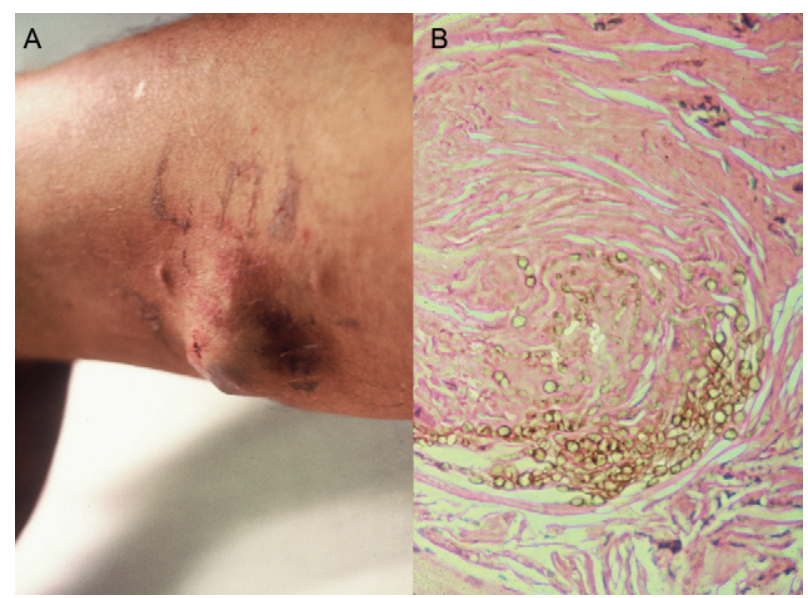

Fig. 1: subcutaneous phaeohyphomycosis by Exophiala jeanselmei (case 17). A: right leg injury in a renal transplant patient; B: histological section of the lesion showing a large number of dematiaceous fungal elements (H\&E: 100X).
Isolation in culture was conducted in $11(61 \%)$ of the cases. In seven cases (38.8\%), no fungal isolation was conducted (Table). The aetiological agents identified were as follows: five Exophiala jeanselmei, two Alternaria sp., one Curvularia, two Cladophialophora sp. and one Colletotrichum gloeosporioides.

C. gloeosporioides is a rare agent of subcutaneous phaeohyphomycosis; therefore, we decided to describe the clinical history of case 12 . The patient was a male, Caucasian, 53 years old and six years post-transplant of the left lung due to secondary emphysema as a consequence of work-related disease. He presented with an ulceration 1.5 $\mathrm{cm}$ in diameter, with a necrotic bottom, close to the left malleolus, which was treated topically with azathioprine, prednisone and cyclosporine for five months without healing. The patient had a history of systemic hypertension and cardiac arrhythmia. He presented with coughing, productive expectoration and a fever of $38-40^{\circ} \mathrm{C}$. The lung tomographic study did not reveal relevant alterations with the exception of a minimal infiltration in the transplanted lung. The direct mycological examination and acid-fast bacillus stain of the sputum were negative. Three haemocultures had negative results as well.

Histopathology and microbiology - A popliteal cyst with unepithelialised wall cavities, fibrosis, granulomatous inflammation with abscess and foreign body granuloma was removed surgically. Acid-fast bacilli were not found in the biopsy material. Microscopy of the biopsy material revealed septate and branched hyaline hyphae with enlarged extremities (by H\&E staining) and the presence of melanin in the fungal wall (by FM staining). A dark colony was isolated in Sabouraud agar at $25^{\circ} \mathrm{C}$. The aetiological diagnosis was possible only by comparative genetic sequencing (sequence: ITS1-5.8S-ITS2 of Colletotrichum in the GenBank database).

Evolution - The fungal lesion was treated by total surgical removal. The patient presented new lesions suggestive of infections with herpes simplex virus in and around the perianal region. The patient died under suspicion of diarrhoea caused by cytomegalovirus infection. An autopsy was not allowed.

Comment - The possibility of phaeohyphomycosis should be considered not only when naturally brown fungal elements are observed under direct microscopy of the clinical specimen, but also when hyaline fungal structures (Mayser et al. 2002) are present in the tissues, which can be mistaken for other mycologic diagnoses (Lopes et al. 1994). Infections caused by species of the Colletotrichum genus have been reported as both phaeohyphomycosis (Matsumoto \& Ajello 1998, Castro et al. 2001) and hyalohyphomycosis (Guarro et al. 1998), although the prevalent diagnosis is phaeohyphomycosis (Guarro et al. 1998).

\section{DISCUSSION}

Phaeohyphomycosis is a clinical entity that is diagnosed when darkly pigmented fungal elements (hyphae, pseudo-hyphae and yeast cells) are observed in a clinical specimen. The subcutaneous presence of the disease distinguishes phaeohyphomycosis from the other two my- 


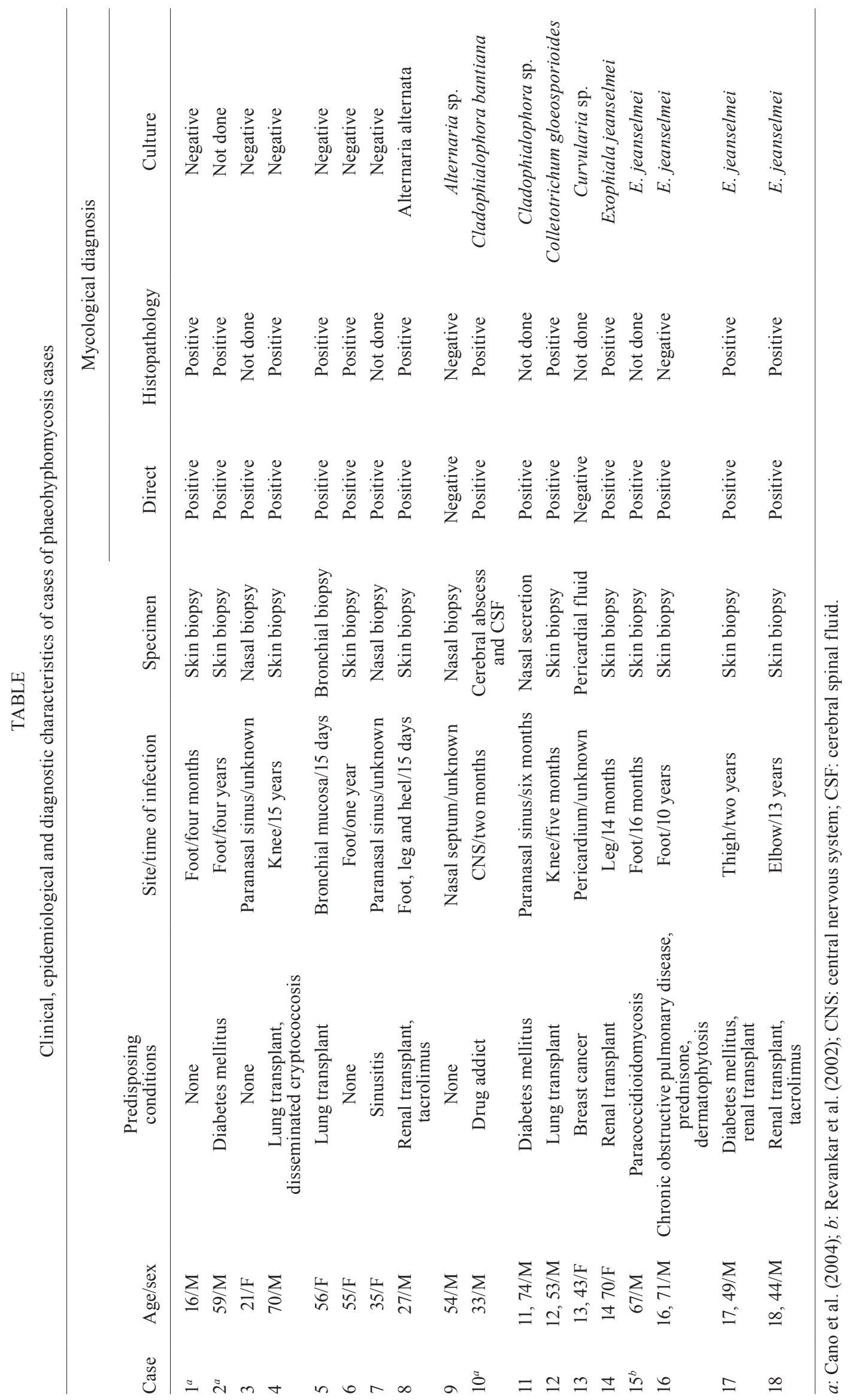




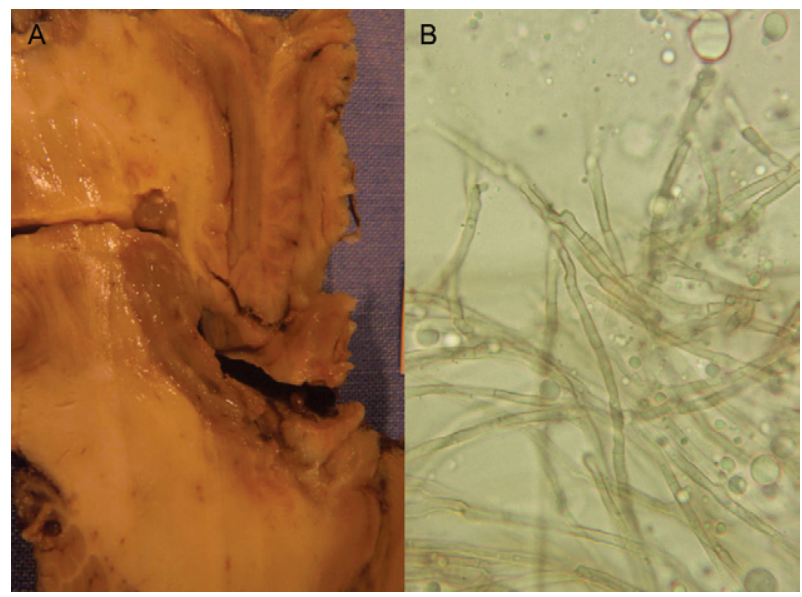

Fig. 2: systemic phaeohyphomycosis (cerebral) by Cladophialophora bantiana (case 10). A: section of brain lesion showing the fourth ventricle with a macroscopic dark colour, due to the dematiaceous hyphae; B: specimen collected from the fourth cerebral ventricle showing large number of dematiaceous hyphae, septate, after clarification with of potassium hydroxide $20 \%$ (H\&E: 400X).

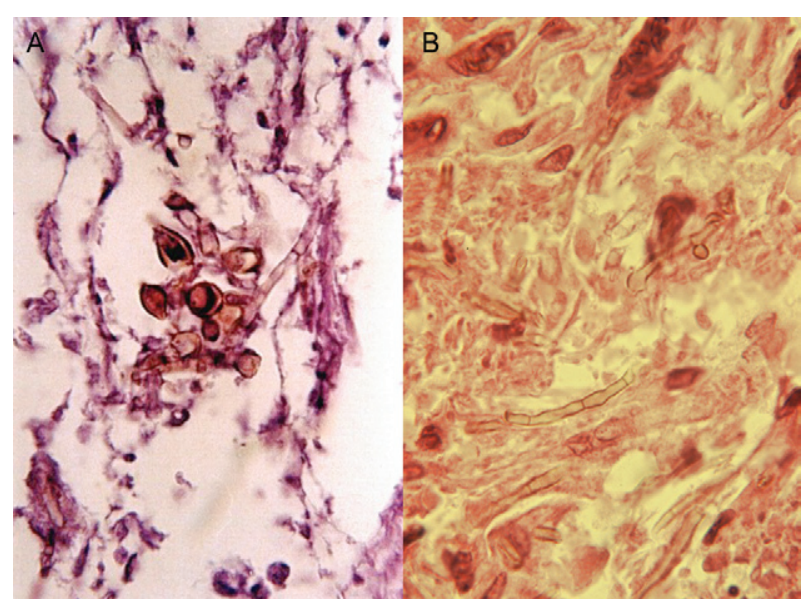

Fig. 3: subcutaneous phaeohyphomycosis. Histological section showing polymorphism of fungal elements (case 6). A: dark yeast cells with thick walls, noting the structure internally divided by a transverse septum (H\&E: 100X); B: a large number of fragments of dematiaceous hyphae (H\&E: 100X).

coses caused by black fungi, chromoblastomycosis and eumycotic mycetoma. In cases of chromoblastomycosis, muriform cells with septation along one or two planes in different levels are observed in the tissue. In mycetoma, the fungus presents in tissues as a microcolony of hyphae in the shape of grains (Matsumoto \& Ajello 1998).

Reviewing the relevant literature in RS, we found cases of phaeohyphomycosis (including cases 1, 2, 10 and 15 of the current series, which have been previously published) as follows: peritoneal, one case caused by Curvularia lunata (Lopes et al. 1994), cutaneous, one case caused by C. lunata (Lopes \& Jobim 1998), subcutaneous, 10 cases, including two cases with only his-

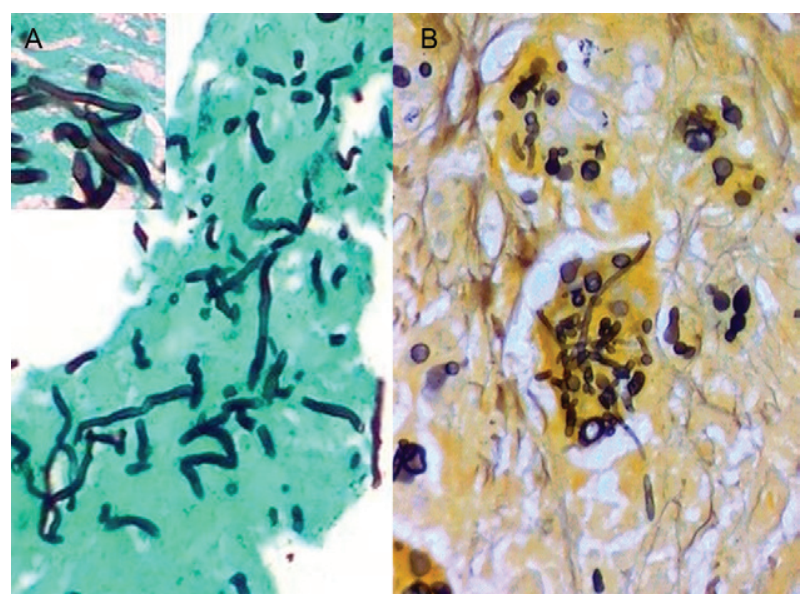

Fig. 4: systemic phaeohyphomycosis (pulmonary) (case 5). Biopsy of the endobronchial lesion. A: presence of pseudohyphae and regular short hyphae (Grocott methenamine silver: 40X); B: tissue section demonstrated the combination of yeast cells, hyphae and pseudo-hyphae with positive melanin reaction (Fontana-Masson staining: 100X).

topathological diagnoses available (Severo et al. 1987), one case caused by E. jeanselmei, one case caused by Phaeoacremonium aleophilum and one caused by Phaeoacremonium rubrigenum (Guarro et al. 2003), and systemic, one case caused by Cladophialophora bantiana (Walz et al. 1997). Re-evaluation of morphological characteristics, supported by phylogenetic analysis, identified $P$. aleophilum as a new fungal species, Phaeoacremonium alvesti (Mostert et al. 2005).

In our series, the aetiological agent was not identified in several cases due to the routine procedure of placing the surgical material directly into formaldehyde, making it impossible to isolate the fungus by culture. In these cases, the diagnosis remained incomplete, as the inflammatory reaction and the tissue presentation of fungal elements are nonspecific in absence of serological testing (Cases 1-7). However, it should be stressed that although histopathological examination cannot identify the aetiological agent, it is the most likely manner in which a general diagnosis of phaeohyphomycosis is initially determined.

Immunosuppressant therapy in patients with solid organ transplants was the primary associated or predisposing condition. It is important to stress that patients treated with tacrolimus more frequently presented with infections by filamentous fungi, presented with much more serious disease and were more resistant to treatment compared with patients suffering another type of immunosuppressive disorder (Pereiro et al. 2004).

E. jeanselmei is expected to be the main aetiological agent of subcutaneous phaeohyphomycosis due to its wide presence in nature. C. bantiana is expected to be the aetiological agent of systemic phaeohyphomycosis with brain damage due to its favourable neurotropism. C. gloeosporioides was an unexpected finding as the cause of subcutaneous phaeohyphomycosis in a patient with a transplanted lung. The aetiological characterisation was possible by 
molecular biology (polymerase chain reaction) only, as it was not possible to conduct a microscopic examination of the fungal colonies. However, in recent years, five species of the Colletotrichum genus have been reported as agents of human infections (Cano et al. 2004).

The frequency of fungal infections is increasing as a consequence of interventions that affect the host's immune system (Revankar 2004). Therefore, the isolation of a fungal agent from any patient, no matter how remote or unusual it may appear, should alert clinical physicians and microbiologists to its potential pathogenicity, especially in the presence of immunosuppression.

\section{ACKNOWLEDGEMENTS}

To Dr Michael R McGinnis, for the etiologic identification of the case 15, to Dr Vlademir Vicente Cantarelli, for the etiologic confirmation of the case 12, and to Dra Alexandra Flávia Gazzoni, for the Fontana-Masson stain.

\section{REFERENCES}

Ajello L, Georg LK, Steigbigel RT, Wang GJK 1974. A case of phaeohyphomycosis caused by a new species of Phialophora. Mycologia 66: 490-498.

Cano J, Guarro J, Gené J 2004. Molecular and morphological identification of Colletotrichum species of clinical interest. J Clin Microbiol 42: 2450-2454.

Castro LGM, Lacaz CS, Guarro J, Gené J, Heins-Vaccari EM, Freitas Leite RS, Arriagada GLH, Reguera MMO, Ito EM, Valente NYS, Nunes RS 2001. Phaeohyphomycotic cyst caused by Colletotrichum crassipes. J Clin Microbiol 39: 2321-2324.

de Hoog GS, Guarro J, Gené J, Figueras MJ 2000. Atlas of clinical fungi, 2nd ed., Centraalbureau voor Schimmelcultures, Utrecht, $1126 \mathrm{pp}$.

Guarro J, Alves SH, Gené J, Grazziotion NA, Mazzuco R, Dalmagro C, Capilla J, Zaror L, Mayayo E 2003. Two cases of subcutaneous infection due to Phaeoacremonium spp. J Clin Microbiol 41: $1332-1336$

Guarro J, Svidzinski TE, Zaror L, Forjaz MH, Gené J, Fischman O 1998. Subcutaneous hyalophhomycosis caused by Colletotrichum gloesporoides. J Clin Microbiol 36: 3060-3065.
Kimura M, McGinnis MR 1998. Fontana-Masson-stained tissue from culture-proven mycoses. Arch Pathol Lab Med 122: 1107-1111.

Lacaz CS, Porto E, Martins JEC, Heins-Vaccari EM, Melo MT 2002. Feo-hifomicose. In CS Lacaz, Tratado de micologia médica, Sarvier, São Paulo, p. 519-561.

Lopes JO, Alves SH, Benevenga JP, Brauner FB, Castro MS, Melchiors E 1994. Curvularia lunata peritonitis complicating peritoneal dialysis. Mycopathologia 127: 65-67.

Lopes JO, Jobim NM 1998. Dermatomycosis of the toe web caused by Curvularua lunata. Rev Inst Med Trop S Paulo 40: 327-328.

Matsumoto T, Ajello L 1998. Agents of phaeohyphomycosis. In L Ajello, RJ Hay (eds.), Topley \& Wilson's microbiology and microbial infections, Arnold, London, p. 503-524.

Mayser F, Nilles M, de Hoog GS 2002. Case report: cutaneous phaeohyphomycosis due to Alternaria alternata. Mycoses 45: 338-340.

McGinnis MR 1983. Chromoblastomycosis and phaeohyphomycosis: new concepts, diagnosis and mycology. J Am Acad Dermatol 8: 1-16.

Mostert L, Groenewald JZ, Summerbell RC, Robert V, Sutton DA, Padhye AA, Crous PW 2005. Species of Phaeoacremonium associated with infections in humans and environmental reservoirs in infected woody plants. J Clin Microbiol 43: 1752-1767.

Pereiro Jr M, Pereiro Ferreirós MM, de Hoog GS, Toribio J 2004. Cutaneous infections caused by Alternaria in patients receiving tacrolimus. Med Mycol 42: 277-282.

Revankar SG 2004. Dematiaceous fungi. Semin Respir Crit Care Med 25: $183-189$.

Revankar SG, Sutton DA, Rinaldi MG 2002. Primary central nervous system phaeohyphomycosis: a review of 101 cases. Clin Infect Dis 34: 467-476.

Rossman SN, Cernoch PL, Davis JR 1996. Dematiaceous fungi are an increasing cause huamn disease. Clin Infect Dis 22: 73-80.

Severo LC, Geyer G, Souza AL, Balbinotti M 1987. Feo-hifomicose subcutânea. Relato dos três primeiros casos do Rio Grande do Sul, Brasil. An bras Dermatol 62: 37-40.

Walz R, Bianchin M, Chaves ML, Cerski MR, Severo LC 1997. Cerebral phaeohyphomycosis caused by Cladophialophora bantiana in a Brazilian drug abuser. J Med Vet Mycol 35: 427-431.

Wood C, Russel-Bell B 1983. Characterization of pigmented fungi by melanin staining. Am J Dermatopathol 5: 71-81. 